\title{
People Work to Sustain Systems: A Framework for Understanding Sustainability
}

\author{
Ian Werkheiser ${ }^{1}$ and Zachary Piso $^{2}$
}

\begin{abstract}
Sustainability is commonly recognized as an important goal, but there is little agreement on what sustainability is, or what it requires. This paper looks at some common approaches to sustainability, and while acknowledging the ways in which they are useful, points out an important lacuna: that for something to be sustainable, people must be willing to work to sustain it. The paper presents a framework for thinking about and assessing sustainability which highlights people working to sustain. It also briefly discusses Integrated Water Resource Management and the example of the California Water Plan to explore what such a perspective brings that is overlooked in other approaches, and how this approach might be pursued. Ultimately, this framework argues that a system can only be described as sustainable if people's work to sustain the system is biophysically possible, socially possible, and if people would freely choose to do the sustaining work. DOI: 10.1061/(ASCE)WR.1943-5452.0000526. ㅇ 2015 American Society of Civil Engineers.
\end{abstract}

Author keywords: Sustainability; Brundtland report; Social justice; Environmental values; Integrated water resource management; California water plan.

\section{Introduction}

Sustainability is already an important goal for many projects, from international development to architectural plans, yet the term itself has different definitions, frameworks, and models (e.g., Altieri 1987; Brundtland 1987; Douglas 1984; Norton 2005; Ott 2003; Seghezzo 2009; Thompson 1992, 2010; Williams and Millington 2004). However, this might not be as problematic as it first appears. A vague, alterable goal like sustainability can act as a boundary object, with a meaning that can shift based on context and experience while having an infrastructure of values and norms. A broad goal can be open to the different perspectives and needs of the people using it, crucially bringing together expert and nonexpert efforts and knowledge (Robinson 2004; Star and Griesemer 1989; Trompette and Vinck 2009). In that spirit, this paper does not attempt to offer a fixed, immutable definition of sustainability. Rather, it will offer a way of looking at sustainability that pulls out some important but under-examined features, and which softens some of the tensions that have emerged between different approaches to sustainability.

"Sustainabilities" will briefly look at a few key approaches to sustainability and point out some of the tensions within and between them, and the scales at which they are most appropriate. "Elements of a Framework for Sustainability" will lay out a new framework for thinking about sustainability, which focuses on the people working to sustain a system. "Sustainability and Integrated Water Resource Management" will discuss the relationship between sustainability as viewed in this new framework and integrated water resource management (IWRM), looking at the California Water

${ }^{1}$ Ph.D. Candidate, Philosophy Dept., Michigan State Univ., 503 South Kedzie Hall, East Lansing, MI 48824 (corresponding author). E-mail: ianwerkheiser@gmail.com

${ }^{2}$ Ph.D. Candidate, Philosophy Dept., Michigan State Univ., 503 South Kedzie Hall, East Lansing, MI 48824.

Note. This manuscript was submitted on May 8, 2014; approved on January 26, 2015; published online on March 4, 2015. Discussion period open until August 4, 2015; separate discussions must be submitted for individual papers. This paper is part of the Journal of Water Resources Planning and Management, (C) ASCE, ISSN 0733-9496/A4015002(7)/\$25.00.
Plan as an example of the possibilities and problems of IWRM. Ultimately this paper will argue that when focusing on people working to sustain something, one sees the importance of a wide variety of considerations which have been previously underexamined in the literature on sustainability.

\section{Sustainabilities}

Approaches to and definitions of sustainability can disagree widely, and are often applicable in very different temporal and spatial scales. However, they usually share an under appreciation of the necessary activity of people to sustain something, which is the focus of this paper. Thus, a few illustrative examples of dominant approaches to sustainability will need to suffice to cover the vast literature of definitions or frameworks. This should not be seen as an exhaustive list.

One prominent version of sustainability is the triple model of three pillars or circles of sustainability-economic, social, and ecological. The simplest triple model conceives of sustainability as resting upon three pillars-environmental, social, and economic factors - with each pillar supporting the sustainability of the society they undergird (Dawe and Ryan 2003). Because this model of sustainability does not suggest interconnections between the three components, multiple circle-based versions have become common (Lozano 2008). The overlapping circle or Venn diagram version of sustainability depicts areas of overlap between the environmental, social, and economic components, with sustainability achieved in the area of the Venn diagram where all components overlap. The three concentric circle model, where the economy is nested within the social system, and the social system within the environment, emphasizes the subsumption of some components within others (Flint and Houser 2001). It is not an entirely settled question as to who first used this triple model, but a likely possibility is that it was first used in a Venn diagram by Miguel Altieri (1987) in his book Agroecology: The scientific basis of sustainable agriculture. In that book, he cites Gordon K. Douglas (1984) and his book Agricultural sustainability in a changing world order. Douglas lays out three different themes of agricultural sustainability that came 
out of the work of the contributors to that book, which he identified as food sufficiency, ecological integrity, and social sustainability. The last term referred to the assault on vibrant rural communities some contributors to Douglas's book saw coming from industrial agriculture (pp. 3-30).

If Altieri (1987) was inspired by these divisions, his three circles are more problematic than Douglas's three areas, not least because they model sustainability generally, rather than the sustainability of agricultural production. It is widely acknowledged that sustainability can be analyzed at multiple scales, but if these three pillars are universalized, they become confusing at the widest scales. For example, if the economy is not taken to be something fixed and external to the system in question, but rather as part of the system whose sustainability is being assessed, it is unclear why the economy should be its own pillar rather than a subset of social sustainability, or perhaps the overlap of society and ecology. What does economic sustainability, as opposed to social sustainability, indicate in ancient Egyptian slave agriculture, when labor is commanded rather than purchased (Thompson 1992)? It is also the case, of course, that this framework only points to different kinds of sustainability, rather than offering a definition itself. Given that limitation and the questions above, it seems that the best use of this triple model is to draw attention to several important areas that might otherwise be neglected, for the purposes of evaluating a particular institution or other entity within a relatively fixed societal background. Indeed, this framework is often used to urge people to consider not only economic sustainability, but social and ecological sustainability as well, something which conversations about systems often fail to do (Pintér et al. 2008).

Another common conception of sustainability comes from the Brundtland Report, also known as Our Common Future, which has become very widely cited and discussed in sustainable development. The Brundtland Report's definition of sustainable development is "Development that meets the needs of the present without compromising the ability of future generations to meet their own needs" (Brundtland 1987). This definition of sustainable development seems to point to sustainability simpliciter as meeting present needs without degrading future capacities for meeting needs. This definition can be, and indeed often is, used with the three pillars of sustainability above, to provide a definition of sustainability within each pillar, or to show how some pillar (usually the environment) constrains other pillars (usually the economy).

However, this definition too has some problems. One is in the problem of what needs are and what it indicates to either meet them now or compromise meeting them for future generations. The Brundtland Report recommends growing industrial production five to 10 times over contemporary levels to meet the needs of the world, which leaves it open to critiques that it sees industrial economic growth as a need. Critics object that this growth is impossible to sustain indefinitely, which would render the report's definition of sustainability impossible to achieve (see e.g., Robinson 2004 for a discussion of this objection). Further, it is not clear how the Brundtland Report's version of sustainability would allow us to ever use any amount of nonrenewable resources, because any rate of consumption would compromise the ability of a future generation sufficiently distant to meet its needs, unless one is committed to the idea that something can be used in a way that looks unsustainable now, but is at a rate "such that they will not be exhausted before alternative sources are available" (Rijsberman and van de Ven 2000). In such cases one can accept that alternatives will be discovered in the future, and assume some rate of discovery. If sustainability is to mean anything, this anticipation of discoveries must be based on a communally justified reason (because otherwise people could say any practice was sustainable by asserting that alternatives and solutions would be developed in the future). However, if there are people who do not consent to these reasons, particularly if they will be affected by exhausting those resources, then continuing to rely on those assumptions is deeply problematic on justice grounds.

Another problem with the Brundtland Report is that to not compromise the ability of future generations to meet their needs, one has to know what those needs will be. This is because making any choice now constrains future choices, in that some possible futures are foreclosed, some made less probable, some made more probable, and some aspects of the future made (at least fairly) certain. Unfortunately, it is not always possible to know if the foreclosed possibilities were ones that future generations needed. One solution to this, favored in adaptive management, is to try to make decisions that leave as many choices in the future open as possible (e.g., Norton 2005), but maximizing alternatives may well require foreclosing the most desirable alternatives. Another approach is to define needs narrowly enough that one can be sure future generations will have needs much like our own (e.g., the need for breathable air), but that does not have the same robust normativity for which Brundtland argues. Because of these problems and the assumptions built into the definition itself (e.g., its intrumentalization of the natural world as resources for meeting human needs), it seems that the best use of this model is to point at the need for thinking intergenerationally on the one hand, and to see sustainability as a commitment to distributive justice for all humans now on the other. It also seems aimed at evaluating policies, especially international policies of development, which is not surprising given the purpose of the commission.

A third conception of sustainability distinguishes between systemic sustainability and goal-directed sustainability. Paul Thompson (1992), in The varieties of sustainability, distinguishes between two importantly different ways that sustainability is used in mainstream and specialist discourse. Sustainability, as a system-describing concept, asks whether a system, with defined boundaries and assumed regularity of external inputs and ability to expel waste, can continue over a specified time scale, or whether internal interactions will disrupt the system (with disruptions being defined as events in which characteristics of the system exceed upper or lower bounds that are predetermined). What one might call systemic sustainability is useful because whether or not a system will fall apart because of internal processes is an important question. It also matches some of our intuitions, in that it seems odd to say that agroecology is unsustainable because the sun will consume the Earth in millions of years; one tends to feel that this "shouldn't count," which Thompson (1992) would say is because it is outside of our defined limits to the system in question.

Of course, systemic sustainability does not cover many of the ways that the term sustainability is used in contemporary discourse, and so Thompson also introduces sustainability as a goaldescribing concept. As Thompson (1992) points out, slavery-based Egyptian agriculture was apparently quite a systemically sustainable form of agriculture, but if this is all sustainability indicates, it seems to undercut arguments for sustainability as a moral obligation (e.g., Howarth 2007). In fact, if it is the case that these slaves would have been better off if the system keeping them oppressed had collapsed, allowing them to flee (as is at least possible), then it seems that systemic sustainability is insufficient for just or moral systems.

If sustainability is instead a goal to be pursued as part of an ethical approach to the system, Thompson (1992) points out there are two ways that this could be the case. The first is that sustainability could be bolted on, in that one only pursues sustainability for systems one judges to be good or just (as happens in various accounts of sustainability, e.g., Swyngedouw et al. 2002). Indeed, Thompson (1992) argues that people should probably prefer a 
world that is less sustainable but more just and full of happy people to a very systemically sustainable but oppressive world full of miserable people. The second is that sustainability could inherently require justice, making it a good goal to pursue in part because it achieves justice, but Thompson (1992) says that he does not see any way this could be the case without cherry-picking our criteria for sustainability (our novel approach, covered in the next section, will attempt in part to do this without unjustified cherry-picking).

This framework does not provide any easy answers to where one should draw the boundaries around a system to speak of its systemic sustainability, nor what time scales one ought to use. Bryan Norton (2005) offers an excellent overview of why boundarydrawing decisions are necessarily normative rather than purely scientific; in short, human communities construct systems depending on the dynamic relationships implicated in human communities' pursuits of what they value. As people better understand how these dynamic relationships are interrelated, they come to understand how the pursuits of particular goals bear on the pursuits of other goals. It is easy to focus on these interrelationships and set aside the values that inform the founding inquiry, but those values must always also be subject to deliberative scrutiny-a science developed to respond to particular values cannot itself show the impossibility of very different values and starting points. Hence, systemic sustainability gives limited guidance on what normative standards ought to be included within goal-directed sustainability, and so both systemic and goal-directed sustainability do not provide much in the way of normative guidance when evaluating a system. Therefore, this framework seems to be most useful when describing systems with fairly obvious borders, at least for the purposes of the people defining the system, and one whose desirability is also not in dispute for those assessing sustainability. That the difference was initially applied to the sustainability of providing food to people through agriculture is therefore appropriate.

\section{Elements of a Framework for Sustainability}

This section will lay out the beginning of an alternative framework for sustainability, one that assesses sustainability by looking at people's ability to sustain the system in question (for ease of reference the authors will refer to systems, but it should be understood that this framework applies to anything from a building to the total of all agricultural practices of a society). The framework is only partial, and so leaves sustainability open enough to serve as a boundary object for future discussion, but it highlights some important qualities of sustainability which ought to be taken into consideration in any more comprehensive definition. The three conceptions of sustainability above, and many other conceptions besides, do not sufficiently address a key component of sustainability - people's ability to sustain a system, or an element of that system. Of course, it is now necessary to define sustain, or to risk simply pushing the vagueness back one step. The expression working to sustain most generally refers to the practices that reproduce a way of life. Communities coordinate these practices through a diversity of means, which have been elaborated as community continuance (Whyte 2013) self-organized community viability (Werkheiser 2014), or environmental heritage (Figueroa 2001). Though they are not identical concepts, all refer to members of a community's ability to continue the elements of their ways of life and institutions they see as important within and between generations, and to change or abandon other elements of their community as they decide in participatorily just ways. So sustaining a system, on this definition, indicates both maintaining and changing its elements such that the system as defined by that community is continued into the future.
This focus on people working to sustain something implies three important requirements for calling something sustainable, based on how people conceive of the agents and the world in which they do their sustaining work. Briefly, according to the framework developed below, a system should only be described as sustainable if people's work to sustain the system is biophysically possible, socially possible, and if people would freely choose to do the sustaining work.

If one thinks of people as biophysical bodies doing their work to sustain a system in a biophysical world, then a necessary requirement for something being sustainable emerges: people's work to sustain a system must be biophysically possible. To say that communities are situated in biophysical environments is simply to say that they depend on inputs from those environments and must offload waste onto those environments. This view of the relationship calls attention to the boundary between the environment and the human system nested within, and when exchanges across this boundary fall out of balance, a metabolic rift risks environmental crises (Foster 1999). A practice which degrades the environment on which it depends cannot be sustained over time no matter how hard people work. Further, the agents themselves are biophysical beings, and work to sustain a system must be possible for them to do as well. If a system can only be sustained as long as people work at an unsustainable rate, it will inevitably collapse. For example, if the system in question is the one providing nutrition to those who sustain it, it must produce at least enough calories expended to sustain it plus those required to keep the people doing the work alive. Of course, biophysical realities can change over time, and be changed with technology to make particular sustainability work effective. Thus, this requirement can refer to a particular time-scale, and can also help guide work to make something sustainable, by showing what changes would need to happen in order for sustaining work to become biophysically possible.

A second requirement emerges when one thinks of people as social beings working to sustain a system in a social world: people's work to sustain a system must be socially possible. At a narrow scale, this requirement can be applied to a particular system operating within a social world, and in such case, the realities of that social world must render it possible for some sustaining work to succeed. For example, if people are working within our current system and thinking about the sustainability of something like a business, then asking about whether it makes enough money to cover its expenses (what might be called economic sustainability in the triple framework) makes sense, because the institutions in our society obviate efforts to sustain businesses which lose too much money every year. Likewise, it may be impossible to sustain a system which runs afoul of too many laws, or which is out of step with social preferences and common wisdom. It is important not to think of this requirement as always setting smaller systems against the backdrop of the larger society's institutions. Sometimes the reverse is true, and the efforts of large social institutions are constrained by local systems. For example, work to scientifically restructure local community practices by distant central planners is often impossible to sustain because the institution of the state is unable to make sense of or see local social realities which resist this intrusion (Scott 1999). At the widest scale, an entire society and all its institutions can be evaluated to see if it meets this requirement. In this case, there would still be a background of social institutions of other societies (and international institutions). However, more focus would be placed on the internal workings of the society's institutions to evaluate if they work together in a way that promotes functional integrity or not, as in the systemic sustainability discussed in the previous section.

This requirement also includes looking at the social beings engaged in the work of sustaining the system. For example, if they 
do not have the capacities (such as education, sufficient time to devote to the project, and others besides) to sustain the system, no amount of effort on their part will be successful until those capacities have been built up (Chaskin 2001; Swyngedouw et al. 2002). Likewise, the ways that people have been shaped as social beings by their social institutions (e.g., in their preferences) will affect what work they do to sustain something, how committed they are to the work, and so on, all of which can render work to sustain a system socially possible or impossible.

As with the first requirement, the second requirement admits to change in circumstances. In this case, however, that change is not effected by technologies of environmental integration and alteration. Rather, the change in both the social actors and the social systems come from changes in social conventions and institutions. For example, a vibrant ecology of native species can be much easier to sustain in the long term if religious or spiritual institutions are changed to construct the practices of environmental restoration and maintenance as a spiritual practice (Van Wieren 2013).

A third requirement for sustainability in this framework emerges when one conceives of people as autonomous reasoners who have and perhaps require justification for their work to sustain a system: it must be the case that people would freely choose to do the sustaining work if given reasons. On purely practical grounds, merely relying on coercive social institutions to get people to do the work of sustaining a system is a much less secure kind of sustainability than one based additionally on good reasons acceptable to all parties. This is most obvious, perhaps, in the case of intergenerational sustainability - if society wants multiple generations, of which the current one is not a part, to continue a project, it is helpful if that project is justifiable with good reasons and values (Dan Steel, personal communication, 2014. For an interesting discussion of intergenerational justifiability, see Steel 2015). To a certain extent, people create future generations of society's own community, and thus have some control over the values of future generations and what collectively counts as a good reason, but counting on the ability to shape future generations with faulty or otherwise insufficient justification is unlikely to be successful. The same is true when society expects anyone else in our current generation to engage in a project, be they citizens from other nations being asked to participate in a climate change regulation scheme, or people working to sustain a particular building by keeping it hooked up to water and power.

This requirement necessitates thinking about justice. First, giving reasons for people to choose an action is itself more procedurally just than coercing people into action. Second, and perhaps more importantly, reasons are often based on justice. A good reason to choose to engage in work to sustain something is that one participated in the decision-making process of defining the system and the work required to sustain it, so this requirement pushes toward participatory justice. Another good reason to choose to engage in work to sustain a system is that the system fairly distributes costs and benefits, so this requirement pushes toward distributive justice. Finally, people are more likely to accept reasons which recognize the uniqueness and importance of their perspective and cultural way of life, so this requirement pushes us toward recognition justice as well (Figueroa 2001; Shrader-Frechette 1991).

Like the first two requirements, this third requirement admits to change. In this case, the change is in what reasons members of the community accept. To pick one example, whether certain kinds of justice appeals have uptake (such as the increasing importance of recognition justice) can indeed change over time. The mechanisms for this change are neither the technologies of the first requirement nor the institutions of the second, but deliberative processes of reason exchange, consciousness raising, and so on.
This third requirement, that a system is sustainable only if the requisite work to sustain that system would be freely chosen by community members, also avoids the objection that justice is perhaps a cherry-picked criterion for sustainability (Thompson 1992). According to this objection, requiring that people choose this work is superfluous to whether the system is indeed sustainable; once the system is shown to meet the first and second requirements, society has demonstrated that the system is indeed sustainable, and shifting to the third requirement amounts to a shift to separate values constrained by the first and second requirements. The crux of the matter is whether the third requirement is in fact a requirement, and whether it is uniquely oriented to justice.

Our view is that all accounts of sustainability must consider human action; human action is the background against which a system is constructed, and human action is the foreground of work that sustains the system as constructed. If all accounts of sustainability do consider human action, then all accounts must imply a theory of human action, or simply an understanding of how and why community members are moved to act. One can imagine a whole range of possible theories of human action drawing from the myriad social sciences that participate in sustainability studies. Economists might understand action to be responsive to incentives; sociologists might understand action to be responsive to social norms and customs. The third requirement offers a humanist orientation to the understanding of human action-human action is properly understood as the sharing and considering of reasons, by which a community member chooses a course forward. Notice that, because it is being offered as an alternative to more mechanistic understandings of human action, this humanist understanding is not an additional criterion. Further, this understanding constrains inquiry according to a minimum commitment to justice. In effect, people face a choice about what understanding of human action will undergird their understanding of sustainability, and some choices are more just than others. It is no more cherry-picking when the humanist theory of human action is adopted than when an economic or sociological theory is chosen. The understanding of sustainability is necessarily incomplete until such a choice is made.

Although these three requirements for sustainability emerge when conceiving of people and the world in which they sustain something differently, they are not mutually exclusive. Rather, they are seen as three separate constraints on what people will work to sustain. These constraints cut across the different models of sustainability discussed in the previous section. Elements of the environmental sustainability tier are contained within the biophysical requirement, but the biophysical requirement also addresses things like the laws of physics and our biophysical bodies, which environmental sustainability has not traditionally emphasized. The social and autonomy requirements cut across the social and economic pillars, in that certain questions germane to those pillars can be thought of as being part of either of the requirements. Looking at people doing work to sustain a system also gives a grounding for when and why those pillars might be relevant concerns, as opposed to simply asserting them as some presentations of that model do without, for example, explaining why it does not include a fourth pillar—geological sustainability perhaps, or cultural sustainability (e.g., Hawkes 2001).

The concerns motivating the Brundtland Report's definition involves biophysical and social constraints on what needs are present now or will be in the future and how people might meet them. It also involves one element of giving reasons, in that people should work toward sustaining a system because they are trying to meet the needs of this generation, though the autonomy requirement includes other justice concerns in it besides. By focusing on people doing work to sustain over time, our approach emphasizes discussion of 
continuing projects into the future, rather than thinking about future generations only as a limiting factor on the way in which society satisfies its current needs as is the case in some understandings of the Brundtland Report.

This focus on people acting to sustain within a set of constraints also covers much of the concerns of systemic sustainability in the first two requirements, but considers those constraints as issuing from the particular problems felt by the sustaining community. The sustainability of the nitrogen cycle, or the sustainability of certain financial practices, become challenges only insofar as the community embarks on practices that encounter these constraints. It also, as discussed above, sees sustainability to be inherently involved in questions of justice, welfare, and so on in the third requirement, thereby avoiding the problems in goal-based sustainability.

This framework also differs from some models of sustainability by taking seriously the agency of people involved in the system. Although it is certainly possible to give due weight to the individual and collective actions of people in an analysis of socioecological systems, they are often underappreciated in terms of their effects. The problem stems from certain conceptions of sustainability, which emphasize the resilience of the sustainable system and commonly highlight total systems in a way that takes human actions as not particularly directed at sustaining that system (Holling 1973; Lebel et al. 2006; Rockström et al. 2014; Walker et al. 2004). For example, when socioecological systems are represented as having particular ecological constraints (e.g., Lebel et al. 2006; Walker et al. 2004), more attention should be paid to why those particular ecological constraints are significant given the social practices that interface with the environment. A meadow is at the bottom of a basin of attraction for some ecosystems, but monocropped corn, or English rose gardens, despite requiring much more input and effort, are more sustainable if those system states are ones that people can, and have good reasons, to sustain.

\section{Sustainability and Integrated Water Resource Management}

The difficulties that arise when trying to achieve sustainability have been recognized by many in water resource management literature and practice as necessitating an adaptive approach. This approach is usually called integrated water resource management (IWRM), and it, like our framework above, takes seriously the importance of people working to sustain a system. Thus, it is useful in this section to show how IWRM fits in with this framework of sustainability.

IWRM has many different definitions, but perhaps the most prominent is provided by the global water partnership (GWP), which defines IWRM as "A process that promotes the coordinated development and management of water, land, and related resources to maximize the resultant economic and social welfare in an equitable manner without compromising the sustainability of vital ecosystems" (Agrawal et al. 2000). This conception of IWRM is often described as being an essential part of sustainable development along the lines of the Brundtland Report, such as in the American Society of Civil Engineers (ASCE) and the United Nations Educational, Scientific, and Cultural Organization's (UNESCO) criteria for sustainability of water resources systems as enabling social goals while preserving the integrity of the water resource systems into the foreseeable future (ASCE and UNESCO 1998). IWRM has also been seen as a way of better integrating the three aspects of the triple model of sustainability, by addressing the bias toward economic sustainability and better acknowledging the importance and interdependence of social and environmental sustainability questions (e.g., Davis 2007). IWRM pursues these goals of integration and sustainable development with an explicit commitment to social justice, including just distribution of benefits, risks, and harms, and just participation by affected stakeholders (Agrawal et al. 2000). The goals of IWRM then are what Thompson might call goaldirected sustainability.

It is useful to briefly examine an example of IWRM in practice before placing it in relation to our framework for sustainability. California has complex, overlapping water laws, policies, and practices. To manage this, the state legislature introduced a mandate to construct an overarching California Water Plan (CWP), administered by the California Department of Water Resources (CDWR) which acts as a collaborative facilitator for stakeholders in public constituencies, different governmental agencies, and scientific bodies to publicly create and adapt the CWP every five years (California Department of Water Resources 2014a). The CWP does not legally mandate actions, but is designed to be a "Collaborative planning framework ... [which] meets California Water Code requirements; guides State investments in innovation and infrastructure; and advances integrated water management and sustainable outcomes" (California Department of Water Resources 2014b). The CDWR, through the CWP, also works to build up communities' capacities to understand and adapt their water resources. To that end, the CWP has recently called for local water plans and measurements of sustainability throughout California, to better integrate local stakeholders (Shilling et al. 2011). As Davis (2007) points out, though the CWP is a powerful model of IWRM, California still suffers serious water unsustainability despite this plan attributable to powerful actors, legacies from previous practices, and environmental problems, and perhaps because of the United States' larger orientation of "net economic development as the primary objective, while complying with the established environmental laws" (p. 441).

IWRM is a particular framework for developing practices (e.g., those found in Hooper 2006) to achieve the kind of coordination of people to achieve sustainability, as laid out in any of the dominant conceptions of that term. Because IWRM begins with deliberation among the people who will need to work to sustain the system, it includes the deliberative conceptualization of the system that will be sustained. Because this system has been conceptualized by reference to what matters to the community, IWRM already takes seriously our third requirement that people would choose to partake in the sustaining of that system. The physical and social constraints that jeopardize this sustainability are identified according to the very values that motivate individuals to conceptualize the system as facing those constraints. The crucial point is that, when IWRM is successful, just participation precedes the identification of shared sustainability challenges, and the coordination of social actions that address these challenges.

Stressing the ways that participation bears on the conceptualization, investigation, and implementation of sustainable management as our framework does helps to clarify two of the main problems that IWRM faces in practice. The first main problem IWRM policies have encountered is the difficulties and complexities that can arise when expanding IWRM to incorporate larger society (Biswas 2004). At the largest scale, it becomes unwieldy to integrate and coordinate all the various institutions and other actors. In the case of California, the problems of producing a single water plan are what motivated the smaller, community-based plans (Shilling et al. 2011), but there remains the larger problem of fitting the CWP into the national landscape. From the perspective of this paper's framework of sustainability, these difficulties reflect social sustainability and justice-based constraints. If the larger society is considered external to the community that deliberates as part of IWRM, then this smaller community faces a social sustainability 
challenge. In that case, the deliberating community must work to reform the social institutions that give rise to the tension between the community's goals and the social actions of the larger society. However, this tension might also be symptomatic of a failure to justly include members of the larger society in the planning process, and additionally the goals of the smaller community are simply misaligned with the goals of others. In such a case, the failure could be resolved through broader deliberation that brings the larger society together in pursuing a shared goal, a shared goal that sufficiently motivates sustaining even at larger scales.

The second major obstacle to implementing IWRM is the costs it imposes on some people and institutions, often those that benefit most from the status quo, and so currently have power to undermine efforts to promote IWRM. Again, this tension can be considered as arising from external social sustainability constraints or justicebased constraints. As IWRM researchers have pointed out, any IWRM program must demonstrate that it can benefit people, and that those negatively affected by the new system will have their concerns addressed and perhaps their losses compensated (e.g., Ballweber 2006; Davis 2007; Howe 2005). Here though, IWRM must be realistic about the social possibility of different ways of organizing society. Even if the larger society was fully included in articulating the sustainability goals, this deliberation may have settled on competing goals that cannot be simultaneously achieved in practice. For instance, if deliberation esteems unfettered accumulation of wealth plus extensive democratic control of resources, it is being unrealistic about how institutions that enable both values will stand in tension. Even though justice concerns are necessarily pertinent to conceptualizing a sustainable system, ensuring just participation is not sufficient for achieving sustainability. Inquiry into the social and biophysical constraints that impair the actualization of the system must still be resolved.

If one takes seriously the role of people working to sustain a system, IWRM provides a useful framework for coordinating this work and perhaps convincing people to engage in it. At the same time, this focus on people's work for sustainability has the potential to make explicit the necessary conditions for IWRM to succeed, and thus to inform early strategies by IWRM coordinators.

\section{Conclusion}

The framework presented in this paper, by focusing on people, their bodies, values, motivations, participation, reasons, and the worlds in which they live, brings in a wider variety of considerations than has been typical in assessments of sustainability in the past. Because of the complexity of the problems facing our society and ecosystem arising out of unsustainable practices, this variety of voices may be a strong argument in its favor. As the above conversation on IWRM shows, there are many resources already in place which can be used to pursue this kind of sustainability, and this framework can likewise improve those efforts as an important step in achieving sustainability in practice.

\section{References}

Agrawal, A., et al. (2000). "Integrated water resource management." TAC Background Paper No. 4, Global Water Partnership, Stockholm, Sweden

Altieri, M. A. (1987). Agroecology: The scientific basis of sustainable agriculture, Westview Press, Boulder, CO.

American Society of Civil Engineers, and United Nations Educational, Scientific, and Cultural Organization. (1998). "Sustainability criteria for water resource systems." ASCE, Reston, VA.
Ballweber, J. (2006). "A comparison of IWRM frameworks: The United States and South Africa." J. Contemp. Water Resour. Educ., 135(1), 74-79.

Biswas, A. K. (2004). "Integrated water resources management: A reassessment." Water Int., 29(2), 248-256.

Brundtland, G. H. (1987). "Brundtland report." Our Common Future, Comissão Mundial.

California Department of Water Resources. (2014a). "About the CDWR." 〈water.ca.gov/aboutus.cfm〉 (Feb. 11, 2015).

California Department of Water Resources. (2014b). "California water plan." 〈waterplan.water.ca.gov〉 (Feb. 11, 2015).

Chaskin, R. J. (2001). "Building community capacity: A definitional framework and case studies from a comprehensive community initiative." Urban Affairs Rev., 36(3), 291-323.

Davis, M. (2007). "Integrated water resource management and water sharing." J. Water Resour. Plann. Manage., 10.1061/(ASCE)07339496(2007)133:5(427), 427-445.

Dawe, N. K., and Ryan, K. L. (2003). "The faulty three-legged-stool model of sustainable development." Conserv. Biol., 17(5), 1458-1460.

Douglass, G. (1984). "The meanings of agricultural sustainability." Agricultural sustainability in a changing world order, G. K. Douglass, ed., The Westview Press, Boulder, CO.

Figueroa, R. M. (2001). "Evaluating environmental justice claims." Forging environmentalism: Justice, livelihood, and contested environments, J. Bauer, ed., Routledge, New York.

Flint, R. W., and Houser, W. L. (2001). Living a sustainable lifestyle for our children's children, iUniverse Press, Bloomington, IN.

Foster, J. B. (1999). "Marx's theory of metabolic rift: Classical foundations for environmental sociology." Am. J. Sociol., 105(2), 366-405.

Hawkes, J. (2001). The fourth pillar of sustainability: Culture's essential role in public planning, Common Ground Publishing, Melbourne, Australia.

Holling, C. S. (1973). "Resilience and stability of ecological systems." Ann. Rev. Ecol. Syst., 4(1), 1-23.

Hooper, B. (2006). Integrated river basin governance: Learning from international experience, International Water Association Publishing, London.

Howarth, R. B. (2007). "Towards an operational sustainability criterion." Ecol. Econ., 63(4), 656-663.

Howe, C. (2005). "The return to the river basin: The increasing cost of jurisdictional externalities.” J. Contemp. Water Resour. Educ., 131(1), 26-32.

Lebel, L., et al. (2006). "Governance and the capacity to manage resilience in regional social-ecological systems." Ecol. Soc., 11(1), 19-39.

Lozano, R. (2008). "Envisioning sustainability three-dimensionally." J. Cleaner Prod., 16(17), 1838-1846.

Norton, B. G. (2005). Sustainability: A philosophy of adaptive ecosystem management, University of Chicago Press, Chicago.

Ott, K. (2003). "The case for strong sustainability." Greifswald's environmental ethics, K. Ott and P. P. Thapa, eds., Steinbecker, Greifswald, DE.

Pintér, L., Bizikova, L., Kutics, K., and Vári, A. (2008). "Developing a system of sustainability indicators for the Lake Balaton region." Tájökológiai Lapok, 6(3), 271-293.

Rijsberman, M. A., and van de Ven, F. H. M. (2000). "Different approaches to assessment of design and management of sustainable water systems." Environ. Impact Assess. Rev., 20(3), 333-345.

Robinson, J. (2004). "Squaring the circle? Some thoughts on the idea of sustainable development." Ecol. Econ., 48(4), 369-384.

Rockström, J., et al. (2014). Water resiliency for human prosperity, Cambridge University Press, Cambridge, U.K.

Scott, J. (1999). Seeing like a state, Yale University Press, New Haven, CT.

Seghezzo, L. (2009). "The five dimensions of sustainability." Environ. Politics, 18(4), 539-556.

Shilling, D., Khan, A., Juricich, R., Fong, V., and Hodge, D. (2011). "The California sustainability indicators framework." California Dept. of Water Resources, 〈waterplan.water.ca.gov〉 (Feb. 11, 2015).

Shrader-Frechette, K. (1991). Risk and rationality: Philosophical foundations for populist reforms, California University Press, Berkeley, CA. 
Star, S. L., and Griesemer, J. (1989). "Institutional ecology, 'translations' and boundary objects: Amateurs and professionals on Berkeley's museum of vertebrate zoology." Soc. Stud. Sci., 19(3), 387-420.

Steel, D. (2015). Philosophy and the precautionary principle, Cambridge University Press, Cambridge, U.K.

Swyngedouw, E., Kaïka, M., and Castro, E. (2002). "Urban water: A political-ecology perspective." Built Environ., 28(2), 124-137.

Thompson, P. B. (1992). "The varieties of sustainability." Agric. Human Values, 9(3), 11-19.

Thompson, P. B. (2010). The agrarian vision: Sustainability and environmental ethics, University of Kentucky Press, Lexington, KY.

Trompette, P., and Vinck, D. (2009). "Revisiting the notion of boundary object, Revue d'Anthropologie des connaissances, 3(1), 3-25.
Van Wieren, G. (2013). Restored to earth: Christianity, environmental ethics, and ecological restoration, Georgetown University Press, Washington, DC.

Walker, B., Holling, C. S., Carpenter, S. R., and Kinzig, A. (2004). "Resilience, adaptability, and transformability in social-ecological systems." Ecol. Soc., 9(2), 5-14.

Werkheiser, I. (2014). "Food sovereignty, health sovereignty, and selforganized community viability." Interdiscip. Environ. Rev., 15(2-3), 134-146.

Whyte, K. P. (2013). "Justice forward: Tribes, climate adaptation and responsibility." Climatic Change, 120(3), 517-530.

Williams, C. C., and Millington, A. C. (2004). "The diverse and contested meanings of sustainable development." Geog. J., 170(2), 99-104. 